\title{
Current Status and Parents' Perception on Horticultural Activity Programs for Preschoolers in Korea
}

\author{
Joo Eun Lee ${ }^{1}$, Jong Won Hong ${ }^{2}$, and Jongyun $\mathrm{Kim}^{3 *}$ \\ ${ }^{1}$ Master Program in Horticulture and Biotechnology, Korea University, Seoul 02841, Korea \\ ${ }^{2}$ Research Professor, Institute of Life Science and Natural Resources, Korea University, Seoul 02841, Korea \\ ${ }^{3}$ Associate Professor, Division of Biotechnology, Korea University, Seoul 02841, Korea
}

\section{ABSTRACT}

This study conducted a survey on 163 parents in Korea to investigate their interest in plants, experience in growing plants, and perception on horticultural activity programs (HAP) for their children. Most children (80.4\%) of the respondents had experience participating in HAPs, and most of their experience occurred during school hours in preschool educational institutions more than once a month (60.3\%). The more interest in plants and experience in growing plants the parents had, the more experience the preschoolers had in participating in HAPs, which implies that the experience of the parents with plants affected their children's participation in HAPs. Parents' most preferred location of HAPs was preschool educational institutions, and most preferred time was school hours with a frequency of more than once a week (57.1\%), which is more frequent than the current status of HAPs in preschool educational institutions. Parents also responded that the most preferred instructors of HAP has are those with a professional background in horticulture. Among the activities in HAP for preschoolers, parents most preferred cooking $(M=4.05)$ activity, and they did not dislike any of the activities. They responded that the facilities for HAP needed to be improved to make HAP more active in preschool educational institutions. Overall, based on the current results, developing suitable HAPs and facilities for preschoolers, fostering professional HAP instructors, and educating parents about horticulture would enhance HAPs in preschool educational institutions, thus providing preschoolers with many benefits of HAPs.

Keywords: early childhood education, gardening, horticultural education, kindergarten, special activities

\section{Introduction}

As urbanization is accelerated by the advancement of the modern society, people today are drifting apart from nature, which resulted in children also being disconnected to nature (Louv, 2007). White (2004) claimed that interaction with nature in early childhood is important for not only the child's development but also the future environment. Moreover, interaction with nature in early childhood has a positive effect on holistic development and can improve active and explorative attitudes (Oh, 2011).

Early childhood is the time in which there is rapid motor ability, cognitive and language development (Kang et al., 2003; Kim et al., 2013), and the time to develop desirable behavioral patterns and attitudes (Chung, 2016), and thus it is important to nurture nature-friendly attitudes through horticultural activities in early childhood (Hong, 2015; Kim and Park, 2014). Horticultural activities in early childhood are known to have positive effects on respect for life (Chung, 2013), development of eco-friendly attitude, scientific inquiry skills and emotional intelligence (Jeong et al., 2009; Kim and Kim, 2018), intellectual development (Jeong et al., 2014), improvement of creativity (Hwang et al., 2011), as well as accepting oneself acknowledging others,

Received: November 4, 2019, Revised: November 29, 2019, Accepted: December 18, 2019

First author: Joo Eun Lee, mew_mew_@hanmail.net, (1) https://orcid.org/0000-0001-8329-9367

*Corresponding author: Jongyun Kim, jongkim@korea.ac.kr, (D) https://orcid.org/0000-0001-8085-9592 
and developing care and cooperation with friends (Kim and Park, 2013).

In parental childcare, the parenting attitudes of parents and their interaction with children have a significant effect on the children's cognitive, language, emotional and social development (Korea Development Institute, 2017; Kwon et al., 2015; Son and Lee, 2008). Previous studies showed that environmental education programs associated with homes had positive effects on preschoolers' eco-friendly attitude (Park, 2010), and parents with more experience of nature in childhood tend to spend more time participating in nature-related activities with their children (Cho and Park, 2013). Recently, horticultural activity programs (HAPs) for preschoolers are provided by various institutions as part of nature-friendly education, and various studies are conducted on their effects on emotional and intelligence development of preschoolers. However, there is almost no research on the effects of parents that can most actively be involved in HAPs for preschoolers.

Therefore, this study was conducted to examine the current state of horticultural activities for preschoolers in Korea and related programs carried out by preschool educational institutions, and determine parents' participation in HAPs for preschoolers depending on their experience in horticultural activities as well as their desired HAPs for preschoolers. This will set the direction and provide activation plans for HAPs for preschoolers so that they can promote emotional stability and healthy growth, and the results will be used as the basic data for development of HAPs for preschools.

\section{Research Methods}

\section{Subjects and methods}

The subjects are parents whose children are enrolled in facilities for preschool education located in metropolitan areas, and the survey was conducted from July 26 to August 23, 2019 in the form of online survey (https://docs.google.com) and direct survey. Out of total 187 copies of the questionnaire, 163 copies with sincere responses were ultimately used as data for analysis.

\section{Measurement tools}

The questionnaire was developed based on previous studies and literatures on horticultural education for early childhood and the general public's interest in plants (Kim, 2019; Kim, 2012; Kim, 2013; Son, 2014), and it was comprised of parents' interest in plants (10 items), parents' plant growing experience (9 items), current state of HAPs for preschoolers (15 items), parents' perception on the need for HAPs for preschoolers (20 items), parents' preference in HAPs for preschoolers (6 items), parents' expected outcomes of HAPs for preschoolers (8 items), activation plans for HAPs for preschoolers ( 7 items), and general characteristics of respondents (6 items; Table 1). For total 81 items,

Table 1. Questionnaire configuration for the survey

\begin{tabular}{|c|c|}
\hline Category & Measure (number of items) \\
\hline Parents' interest in plants & Likert scale $(10)$ \\
\hline Parents' plant growing experience & Likert scale (9) \\
\hline \multirow[t]{2}{*}{ Current state of HAPs for preschoolers } & Likert scale (4) \\
\hline & Nominal scale (11) \\
\hline \multirow[t]{2}{*}{ Parents' perception on the need for HAPs for preschoolers } & Likert scale (19) \\
\hline & Nominal scale (1) \\
\hline Parents' preference in HAPs for preschoolers & Likert scale (6) \\
\hline Parents' expected outcomes of HAPs for preschoolers & Likert scale (8) \\
\hline Activation plans for HAPs for preschoolers & Likert scale (7) \\
\hline General characteristics of respondents & Nominal scale (6) \\
\hline Total & 81 items \\
\hline
\end{tabular}

Note. HAPs $=$ Horticultural Activity Programs. 
which consist of 63 items using a 5-point Likert scale and 18 items of a nominal scale, we conducted frequency analysis, descriptive statistics, cross-tabulation analysis, independent samples t-test, and one-way ANOVA to analyze the general characteristics of respondents and parents' perception on HAPs for preschoolers, and used a Scheffé test for posttest analysis. Cronbach's $\alpha$ of 10 items about parents' interest in plants was .880 , indicating that parents' interest in plants was an item that meets the internal reliability. All statistical analysis was conducted using the SPSS 25.0 statistical package (IBM Co., Armonk, NY, USA).

\section{Results and Discussion}

\section{Demographic characteristics}

The survey results showed that there were 11 male (6.7\%) and 152 female respondents (93.3\%), and most were in their 30s (58.9\%) and 40s (26.4\%; Table 2). By education level, $87.8 \%$ of respondents graduated university or higher. Most families were comprised of parents and children $(91.4 \%)$, and most had either one or two children
(89.6\%; Table 2).

\section{Current state of HAPs for preschoolers}

The current state of horticultural activities for preschoolers showed that $65.6 \%$ of respondents said their children are currently participating in horticultural activities, and $79.1 \%$ responded that their children have experience participating in the past. Only $19.6 \%$ responded that their children do not have experience, indicating that most children have experience in horticultural activities either in the past or present (Table 3).

Places where horticultural activities were carried out for preschoolers were determined through multiple responses, and the results showed that most of the respondents carried out horticultural activities in preschool educational institutions (78.5\%) and botanical gardens (73.6\%), followed by home $(63.8 \%)$, theme parks $(61.3 \%)$, private activity farms $(57.1 \%)$, and weekend farms (52.8\%; Table 3$)$. These results showed that HAPs for preschoolers were carried out in various places including preschool educational institutions and even at home. In particular, private activity farms are places for children to visit the producing areas

Table 2. General characteristics of respondents

\begin{tabular}{|c|c|c|c|}
\hline \multicolumn{2}{|c|}{ Category } & Frequency (n) & Percent $(\%)$ \\
\hline \multirow{2}{*}{ Gender } & Male & 11 & 6.7 \\
\hline & Female & 152 & 93.3 \\
\hline \multirow{4}{*}{ Age } & $20 \mathrm{~s}$ & 22 & 13.5 \\
\hline & $30 \mathrm{~s}$ & 96 & 58.9 \\
\hline & $40 \mathrm{~s}$ & 43 & 26.4 \\
\hline & 50 s or more & 2 & 1.2 \\
\hline \multirow{3}{*}{ Education } & High school & 20 & 12.3 \\
\hline & University & 115 & 70.6 \\
\hline & Graduate school & 28 & 17.2 \\
\hline \multirow{3}{*}{ Family composition } & Parents + children & 149 & 91.4 \\
\hline & Grandparents + parents + children & 9 & 5.5 \\
\hline & One parent + children & 5 & 3.1 \\
\hline \multirow{4}{*}{ Number of children } & 1 & 60 & 36.8 \\
\hline & 2 & 86 & 52.8 \\
\hline & 3 & 15 & 9.2 \\
\hline & 4 or more & 2 & 1.2 \\
\hline Total & & 163 & 100.0 \\
\hline
\end{tabular}


of regional specialties (strawberries, peanuts, sweet potatoes, cabbages, radishes, pears, blueberry farms) that can induce children's interest and provide them with experience in growing and harvesting seasonal garden crops. Recently, the 6th industrialization of farms in Korea and the certification of educational farms by Rural Development Administration (2018) are resulting in activation of farm activity programs.

For the question of whether there is a HAP at the preschool educational institution in which the children are currently enrolled, $74.2 \%$ responded that HAPs were carried out in preschool educational institution. The frequency of HAPs was mostly at least once a month (60.3\%), while
24.0\% were carrying out HAPs 1-4 times a year (Table 3 ). This is similar to a previous study on teachers of preschool educational institutions (Kim, 2012), where 64.3\% of the institutions carried out HAPs at least once a month.

The time organized for HAPs at preschool educational institutions was mostly during the school hours (51.2\%), and $15.7 \%$ carried out HAPs through field trips and picnics. A previous study by Park (2001) showed that HAPs carried out in preschool educational institutions are mostly through picnics or field trips, but recent studies (Chi et al., 2018; Kim, 2012) reported that HAPs are partially included in school hours, which indicates that the portion of HAPs has

Table 3. Status of HAPs for preschoolers

\begin{tabular}{|c|c|c|c|}
\hline Category & & Frequency (n) & Percent $(\%)$ \\
\hline \multirow{2}{*}{ Currently involved in horticultural activities } & Yes & 107 & 65.6 \\
\hline & No & 56 & 34.4 \\
\hline \multirow{2}{*}{ Having experience of horticultural activities } & Yes & 129 & 79.1 \\
\hline & No & 34 & 20.9 \\
\hline \multirow{3}{*}{ HAPs available in preschool } & Yes & 121 & 74.2 \\
\hline & No & 27 & 16.6 \\
\hline & Don't know & 15 & 9.2 \\
\hline \multirow{6}{*}{$\begin{array}{l}\text { Places for horticultural activities } \\
\text { (multiple answers) }\end{array}$} & Amusement parks & 100 & 61.3 \\
\hline & Botanic gardens & 120 & 73.6 \\
\hline & Activity farms & 93 & 57.1 \\
\hline & Preschools & 128 & 78.5 \\
\hline & Weekend farms & 86 & 52.8 \\
\hline & Home & 104 & 63.8 \\
\hline \multirow{8}{*}{$\begin{array}{l}\text { Frequency of HAPs in preschool } \\
\qquad(\mathrm{n}=121)\end{array}$} & Every day & 5 & 4.1 \\
\hline & Twice a week & 6 & 5.0 \\
\hline & Once a week & 20 & 16.5 \\
\hline & Twice a month & 13 & 10.7 \\
\hline & Once a month & 29 & 24.0 \\
\hline & 5-10 times per year & 3 & 2.5 \\
\hline & 1-4 times per year & 29 & 24.0 \\
\hline & Don't know & 16 & 13.2 \\
\hline \multirow{5}{*}{$\begin{array}{l}\text { Schedule of HAPs in preschool } \\
\qquad(\mathrm{n}=121)\end{array}$} & During class hours & 62 & 51.2 \\
\hline & During outdoor activity hours & 19 & 15.7 \\
\hline & During special activity hours & 33 & 27.3 \\
\hline & Don't know & 4 & 3.3 \\
\hline & Others & 3 & 2.5 \\
\hline Total & & 163 & 100.0 \\
\hline
\end{tabular}

Note. HAPs $=$ Horticultural Activity Programs. 
increased during class hours of preschool educational institutions as shown in this study (Table 3).

\section{Characteristics according to parents' interest in plants and plant growing experience}

The survey results showed that when parents have more interest in plants and plant growing experience, their children also tend to have more experience in horticultural activities $(p=.024)$. When parents' interest in plants was very high (mean 4-5 points), their children's experience in horticultural activities was $100.0 \%$, followed by $3-4$ points $(87.7 \%), 2-3$ points $(74.4 \%)$, and $1-2$ points $(64.3 \%)$, which varied depending on the parents' interest in plants (Table 4). Children's experience in horticultural activities according to parents' plant growing experience also showed similar results. For parents with the mean of 4-5 points in plant growing experience, their children all had experience in horticultural activities, whereas for parents with the mean of 1-2 points in plant growing experience, only $50 \%$ of their children had experience (Table 4). This result is similar to previous research stating that the more parents have experience in nature during their childhood, the more time they spend in nature with their children (Cho and Park, 2013), which indicates that parents' interest in plants and experience affects children's plant education. Therefore, increasing parents' interest in plants and plant growing experience through education for parents will help promote horticultural activities for preschoolers.

\section{Parents' perception on HAPs for preschoolers}

Parents' perception on the need for HAPs for preschoolers had the mean score of 3.79 on a 5-point Likert scale. We compared parents' perception on the need for HAPs for preschoolers depending on the children's participation in horticultural activities. It was found that there was no significant difference between when the children had experience in horticultural activities (mean 3.84) and when they did not (mean 3.59). Thus, the respondents had positive views about the need for HAPs for preschoolers regardless of the children's participation in horticultural activities (Table 5).

As for the frequency of HAPs for preschoolers desired

Table 4. Experience of participating in HAPs of preschoolers by parents' interest in plants and plant growing experience

\begin{tabular}{|c|c|c|c|c|}
\hline \multirow{2}{*}{ Category } & \multirow{2}{*}{ Scale range } & \multicolumn{2}{|c|}{ Preschoolers' participation in HAPs (\%) } & \multirow{2}{*}{$\begin{array}{c}\chi^{2} \\
(p \text {-value })\end{array}$} \\
\hline & & Yes & No & \\
\hline \multirow{4}{*}{$\begin{array}{l}\text { Parents' interest in } \\
\text { plants }\end{array}$} & $1-2$ & $9(64.3)$ & $5(35.7)$ & \multirow{4}{*}{$\begin{array}{l}9.452 \\
(.024)\end{array}$} \\
\hline & $2-3$ & $58(74.4)$ & $20(25.6)$ & \\
\hline & $3-4$ & $50(87.7)$ & $7(12.3)$ & \\
\hline & $4-5$ & $14(100.0)$ & $0(0.0)$ & \\
\hline \multirow{4}{*}{$\begin{array}{c}\text { Parents' plant growing } \\
\text { experience }\end{array}$} & $1-2$ & $4(50.0)$ & $4(50.0)$ & \multirow{4}{*}{$\begin{array}{l}8.522 \\
(.036)\end{array}$} \\
\hline & $2-3$ & $41(74.5)$ & $14(25.5)$ & \\
\hline & $3-4$ & $81(85.3)$ & $14(14.7)$ & \\
\hline & $4-5$ & $5(100.0)$ & $0(0.0)$ & \\
\hline \multicolumn{2}{|c|}{ Total } & $131(80.4)$ & $32(19.6)$ & \\
\hline
\end{tabular}

Note. HAPs $=$ Horticultural Activity Programs.

Table 5. Parents' perception on the needs for HAPs for preschoolers by the preschoolers' participation in HAPs

\begin{tabular}{cccccc}
\hline \multirow{2}{*}{ Category } & & \multicolumn{3}{c}{ Needs for HAPs for preschooler } \\
\cline { 3 - 6 } & & $\mathrm{M}$ & $\mathrm{SD}$ & $t$ & $p$-value \\
\hline \multirow{2}{*}{ Preschoolers' participation in HAPs } & Yes & 3.84 & 0.747 & 1.705 & .090 \\
& No & 3.59 & 0.746 & & \\
\hline
\end{tabular}

Note. HAPs $=$ Horticultural Activity Programs. 
by parents, $57.1 \%$ of the parents wanted the program to be carried out at least once a week, but $50.5 \%$ responded that the program was actually carried out less than once a month according to the survey on the current state of HAPs for preschoolers (Table 6). There was a gap between the actual state of HAPs for preschools and the frequency desired by respondents, which proves that parents want more regular HAPs for preschoolers than the present $(p$ $<.001)$. This result is similar to a previous study on teachers (Kim, 2012), indicating that not only parents but also preschool teachers think there is a need for more regular HAPs for preschoolers. Based on this result, it is necessary to conduct research on the frequency of HAPs for preschoolers for effective horticultural education.

Parents perceived that the most suitable time and place to carry out HAPs for preschoolers is during school hours at preschool educational institutions (mean 3.74), followed by extracurricular activity hours at preschool educational institution (mean 3.68), picnics and field trips of preschool educational institutions (mean 3.52), horticultural activities carried out at home with family (mean 3.44), and horticultural activities carried out outdoors with family (mean 3.34;
Table 7). The respondents preferred HAPs for preschoolers during school hours of preschool educational institutions, while they relatively less preferred horticultural activities carried out outdoors with family $(p<.001)$. According to Cho and Park (2013), if the mother has little or average experience of nature in childhood, she perceives lack of knowledge in nature-related activities with children as a difficulty, which supports the results of this study. With the recent implementation of the 52-hour workweek system, dual-career couples can now have relatively more free time after work. Therefore, developing and supplying HAPs for them to make good use of this time and participate with their children will not only lessen the parents' burden about their children's horticultural education but also promote and spread high-quality horticultural education for preschoolers.

The most suitable place for HAPs for preschoolers perceived by parents was preschool educational institutions (mean 3.92), followed by botanical gardens (mean 3.65), home (mean 3.48), weekend farms (mean 3.48), activity farms (mean 3.37), and theme parks (mean 3.04; Table 8). In particular, even though weekend farms, activity farms

Table 6. The difference between the current frequency of HAPs in preschool and desired frequency of HAPs in preschool by parents

\begin{tabular}{|c|c|c|c|c|c|c|c|c|}
\hline \multirow[b]{2}{*}{ Category } & \multicolumn{7}{|c|}{ Frequency of HAPs (\%) } & \multirow{2}{*}{$\begin{array}{c}\chi^{2} \\
(p \text {-value })\end{array}$} \\
\hline & Everyday & $\begin{array}{c}\text { Twice a } \\
\text { week }\end{array}$ & $\begin{array}{c}\text { Once a } \\
\text { week }\end{array}$ & $\begin{array}{l}\text { Twice a } \\
\text { month }\end{array}$ & $\begin{array}{l}\text { Once a } \\
\text { month }\end{array}$ & $\begin{array}{c}5-10 \\
\text { per year }\end{array}$ & $\begin{array}{c}1-4 \\
\text { per year }\end{array}$ & \\
\hline Current frequency $(n=105)$ & $5(4.8)$ & $6(5.7)$ & $20(19.0)$ & $13(12.4)$ & $29(27.6)$ & $3(2.9)$ & $29(27.6)$ & 40.258 \\
\hline Parents' desired frequency $(n=163)$ & $13(8.0)$ & $30(18.4)$ & $50(30.7)$ & $22(13.5)$ & $40(24.5)$ & $1(0.6)$ & $7(4.3)$ & $(<.001)$ \\
\hline Total & $18(6.7)$ & $36(13.4)$ & $70(26.1)$ & $35(13.1)$ & $69(25.7)$ & $4(1.5)$ & $36(13.4)$ & \\
\hline
\end{tabular}

Note. HAPs $=$ Horticultural Activity Programs.

Table 7. Parents' perception on the appropriate schedule for HAPs for preschoolers

\begin{tabular}{|c|c|c|c|c|}
\hline \multirow{2}{*}{ Category } & \multicolumn{4}{|c|}{ Appropriate time for HAPs for preschoolers HAP for preschoolers } \\
\hline & M & SD & $\mathrm{F}$ & $p$-value \\
\hline During class hours in preschool & $3.74 \mathrm{a}^{\mathrm{z}}$ & 0.90 & & \\
\hline During special activity hours in preschool & $3.68 \mathrm{a}$ & 0.90 & & \\
\hline During outdoor activity hours in preschool & $3.52 \mathrm{ab}$ & 0.93 & 5.423 & $<.001$ \\
\hline At home with family & $3.44 \mathrm{ab}$ & 0.96 & & \\
\hline Outdoor activities with family & $3.34 \mathrm{~b}$ & 0.93 & & \\
\hline
\end{tabular}

Note. 5-point Likert scale was used. HAPs $=$ Horticultural Activity Programs.

${ }^{\mathrm{z}}$ Means followed by the same letter in the column do not differ statistically at the .05 level for Scheffe test. 
and theme parks can be regarded as suitable places for HAPs for preschoolers, the respondents preferred them less than home mostly due to physical and environmental constraints as well as lack of continuous programs. Rural Development Administration (2008) has already been training educational farm instructors and developing and supplying systematic programs for continuous and self-directed learning at activity farms, but weekend farms or theme parks still seem to lack systematic programs. Therefore, it is necessary to develop continuous programs for the characteristics of each place aside from activity farms.

The most qualified instructors in HAPs for preschoolers perceived by parents were professional horticultural education instructors (mean 4.00), and the least qualified were homeroom teachers (mean 3.18; Table 9). Currently, various extracurricular activities are carried out in preschool educational institution, and teachers of extracurricular activities with specialized knowledge in each field are guiding the preschoolers. Accordingly, the respondents think that instructors with expertise in horticultural knowledge are most suitable for preschool horticultural education as well, and consider knowledge and expertise as the most important element. According to Kim et al. (2017), knowledge and expertise had the biggest impact on how a certain occupational group as expert or specialist. The results of this study also reveal parents' demand for knowledge and expertise of instructors in HAPs for preschoolers. Based on the results, intellectuals with horticulture-related expertise such as welfare horticultural therapists, urban agriculture managers and forest education experts must pay more attention to HAPs for preschoolers and develop programs, train specialized instructors, and work on publicity.

Parents' most preferred activity in HAPs for preschoolers was cooking (mean 4.05; Table 10), which is similar to the result of a previous study on teachers of preschool educational institutions (Kim, 2012) that cooking (mean 4.04) and plant growing (mean 3.88) showed the highest preference. This proves that parents and teachers share a similar preference in programs. According to Lee (2017), preschoolers' cooking activities in association with gardening had pos-

Table 8. Parents' perception on the appropriate place for HAPs for preschoolers

\begin{tabular}{lccc}
\hline & \multicolumn{3}{c}{ Appropriate place for HAPs for preschoolers HAP for preschoolers } \\
\cline { 2 - 4 } & $\mathrm{M}$ & $\mathrm{SD}$ & $\mathrm{F}$ \\
\hline Preschool & $3.92 \mathrm{a}^{\mathrm{z}}$ & 0.81 & \\
Botanic garden & $3.65 \mathrm{ab}$ & 0.99 & \\
Home & $3.48 \mathrm{~b}$ & 0.98 & 14.948 \\
Weekend farm & $3.48 \mathrm{~b}$ & 0.98 & $<.001$ \\
Activity farm & $3.37 \mathrm{bc}$ & 1.04 & \\
Amusement park & $3.04 \mathrm{c}$ & 1.01 & \\
\hline
\end{tabular}

Note. 5 -point Likert scale was used. HAPs $=$ Horticultural Activity Programs.

${ }^{\mathrm{z}}$ Means followed by the same letter in the column do not differ statistically at the .05 level for Scheffe test.

Table 9. Parents' perception on the appropriate qualifications of a teacher for HAPs in preschool

\begin{tabular}{lccc}
\hline \multicolumn{1}{c}{ Category } & \multicolumn{2}{c}{ Appropriate qualifications of a teacher for HAPs in preschool } \\
\cline { 2 - 4 } & $\mathrm{M}$ & $\mathrm{SD}$ & $\mathrm{F}$ \\
\hline A homeroom teacher & $3.18 \mathrm{~b}^{\mathrm{z}}$ & 0.95 & \\
A horticultural education trained homeroom teacher & $3.85 \mathrm{a}$ & 0.85 & 26.932 \\
A professional horticultural education teacher & $4.00 \mathrm{a}$ & 0.88 & $<.001$ \\
A horticultural education trained teacher with qualified of early childhood education & $3.96 \mathrm{a}$ & 0.89 & 0.99 \\
A family member with plant-growing experience & $3.37 \mathrm{~b}$ & \\
\hline
\end{tabular}

Note. 5-point Likert scale was used. HAPs $=$ Horticultural Activity Programs.

${ }^{\mathrm{z}}$ Means followed by the same letter in the column do not differ statistically at the .05 level for Scheffe test. 
Table 10. Parents' preference for HAPs for preschoolers

\begin{tabular}{|c|c|c|c|c|}
\hline \multirow{2}{*}{ Category } & \multicolumn{4}{|c|}{ Preference for the HAPs for preschoolers } \\
\hline & M & SD & $\mathrm{F}$ & $p$-value \\
\hline Cooking (with own grown plant) & $4.05 \mathrm{a}^{\mathrm{z}}$ & 0.82 & \multirow{6}{*}{3.922} & \multirow{6}{*}{.002} \\
\hline Outdoor gardening (fruits, vegetables) & $3.99 \mathrm{ab}$ & 0.82 & & \\
\hline Visiting farm (strawberry, sweet potato) & $3.91 \mathrm{ab}$ & 0.86 & & \\
\hline Outdoor gardening (ornamental plants) & $3.86 \mathrm{ab}$ & 0.81 & & \\
\hline Indoor gardening & $3.79 \mathrm{ab}$ & 0.88 & & \\
\hline Plant craft activities & $3.69 \mathrm{~b}$ & 0.98 & & \\
\hline
\end{tabular}

Note. 5 -point Likert scale was used. HAPs $=$ Horticultural Activity Programs.

${ }^{\mathrm{z}}$ Means followed by the same letter in the column do not differ statistically at the .05 level for Scheffe test.

Table 11. Parents' expectation of HAPs as educational program for preschoolers

\begin{tabular}{|c|c|c|c|c|}
\hline \multirow{2}{*}{ Category } & \multicolumn{4}{|c|}{ Educational expectation of HAPs for preschoolers } \\
\hline & M & SD & $\mathrm{F}$ & $p$-value \\
\hline Enhanced morality and exploring ability would help preschoolers' creativity development. & 4.20 & 0.75 & & \\
\hline Preschoolers would learn how to cooperate with another individual, society and nature. & 4.07 & 0.83 & & \\
\hline Preschoolers would preserve nature. & 4.21 & 0.78 & & \\
\hline Experiencing nature would bring emotional stability of preschoolers. & 4.29 & 0.76 & & \\
\hline $\begin{array}{l}\text { Horticultural activity program would enrich preschooler's expressing ability through making } \\
\text { activity or expressing activity. }\end{array}$ & 4.21 & 0.76 & 0.993 & .435 \\
\hline Preschoolers would be more interested in nature-toy than usually fixed toy. & 4.20 & 0.79 & & \\
\hline Experience would affect intelligent development through enhanced exploring trait. & 4.23 & 0.70 & & \\
\hline Preschoolers would develop the sense and intelligence through touching and feeling. & 4.20 & 0.73 & & \\
\hline
\end{tabular}

Note. 5-point Likert scale was used. HAPs $=$ Horticultural Activity Programs.

itive effects on their happiness and emotional intelligence. Therefore, it is necessary to develop activities like gardening or cooking with vegetables from the garden to meet the parents' needs in developing HAPs for preschoolers, and using previous studies as the basic data will create a good synergy.

All items of expected educational outcome from HAPs for preschoolers showed the mean between 4 and 5 points. The respondents expected positive effects such as development of the five senses, cognitive development, emotional stability, cooperative spirit (teamwork), morality, inquiry skills and eco-friendly attitude of preschoolers regardless of items of expected outcomes (Table 11). In particular, they expected that HAPs would have positive effects on emotional stability (mean 4.29) and cognitive development (mean 4.23), and thus it seems necessary to develop horticultural programs based on these two elements according to the parents' needs. Furthermore, it was found in previous studies that HAPs for preschoolers have positive effects on children's language comprehension, scientific inquiry skills, emotional intelligence, sociality, and eco-friendly attitude ( $\mathrm{Im}$ et al., 2013; Jeong et al., 2011; Jung et al., 2017), thereby meeting parents' expectations. However, systematic programs according to each expected outcome are sill not developed enough, which is why it is necessary to develop such programs.

To activate HAPs for preschoolers, most parents responded that it is necessary to improve the environment for horticultural activities in preschool educational institutions (mean 3.96), whereas the least thought encouraging parents' participation was necessary (mean 3.70) (Table 12). The post-hoc Scheffé test results showed that there was no significant difference, and all items scored 3 points or higher, indicating that the respondents had positive 
Table 12. Parents' needs for the activation of HAPs for preschoolers

\begin{tabular}{|c|c|c|c|c|}
\hline \multirow{2}{*}{ Category } & \multicolumn{4}{|c|}{ Activation of HAPs for preschoolers } \\
\hline & M & SD & $\mathrm{F}$ & $p$-value \\
\hline Consistent with the current curriculum of preschool & 3.94 & 0.82 & & \\
\hline Improvement of the facility for HAPs in preschool & 3.96 & 0.81 & & \\
\hline Enabling the development and dissemination of HAPs & 3.93 & 0.79 & & \\
\hline Governmental support will be needed & 3.86 & 0.89 & 2.034 & .058 \\
\hline Strengthen the links among the communities (activity farm, weekend farm) & 3.94 & 0.80 & & \\
\hline Participation in teacher training and horticultural education should be supported & 3.85 & 0.77 & & \\
\hline Encouragement for the parents to participate in HAPs & 3.70 & 0.88 & & \\
\hline
\end{tabular}

Note. 5-point Likert scale was used. HAPs $=$ Horticultural Activity Programs.

views about all items as the plans to activate horticultural activities for preschoolers. Based on these results, it can be found that parents want preschool educational institutions or the community to perform the role of providing horticultural education for preschoolers rather than teaching their children themselves. Therefore, preschool educational institutions or the community must provide high-quality HAPs and the environment for parents and children to participate together, so that parents can fulfill their role as the main agent of children's education.

\section{Conclusion}

This study discovered that most parents had positive views about HAPs for preschoolers, and parents' interest in plants or experience affect their children's horticultural activities. To promote horticultural activities for preschoolers based on this result, it is necessary to provide parents with horticultural education to increase their interest in plants and growing experience. Furthermore, developing high-quality HAPs for preschoolers in which both parents and children can participate together will create a synergy of education for both parents and children.

Recently, with the emergence of a neologism called 'work-life balance', the 52-hour workweek system has been introduced for work and life balance that enabled even dual-career couples to relatively have more free time. As they have more time to spend with family, it seems necessary to provide various HAPs as well as venues and professional instructors for them so that parents and children can make better use of that free time. In particular, for horticultural education of preschoolers, there must be support from preschool educational institutions or the community so that parents can perform as the main agent of horticultural education for their children. To this end, it is necessary to support HAPs for preschoolers, develop programs according to the characteristics of each place, and train instructors with expertise in horticulture. This will help develop the programs into more effective HAPs for preschoolers as well as educational programs that will develop emotional stability and promote healthy growth of preschoolers.

\section{References}

Chi, S.A., C.Y. Kim, and J.H. Jung. 2018. An analysis of the status and teachers awareness of horticulture education for young children. Early Child. Educ. Res. Rev. 22(5):191-217. https://doi.org/10.32349/ECERR.2 018.10.22.5.191

Cho, H.S. and S.Y. Park. 2013. The current status and demands for nature experience activities of child and mothers at home. Early Child. Educ. Res. Rev. 17(4):421-445.

Chung, M.R. 2013. Developing and applying a life-esteemed education program based on nature friendly model for young children's life-esteemed literacy. Korean J. Early Child. Educ. 33(3):319-347. https://doi.org/10.18023/kje ce.2013.33.3.014

Chung, O.B. 2016. Development in early childhood. Seoul, Korea: Hakjisa.

Hong, J. 2015. The effects of the nature friendly education 
activities on young children`s happiness and environmental friendly attitude. J. Future Early Child. Educ. 22(4):413-432.

Hwang, H.J., E.J. Jang, and C.H. Pak. 2011. The effects of horticultural activities program applied creativity techniques on young children's creativity. J. Korean Soc. People Plant Environ. 14(3):155-162.

Im, E.A., M.R. Eum, P.J. Kim, S.H. Hong, and K.C. Son. 2013. Effect of vegetable gardening with horticultural therapy on development of children's emotional intelligence, scientific investigation and sociality (Abstr.). Korean J. Hortic. Sci. Technol. 31(Suppl. I):207.

Jeong, M.I., E.S. Jea, S.M. Lee, and B.Y. Yi. 2014. Effects of horticultural activities program focusing on fourseason ornamental rooftop garden to be released on preschoolers' creative thinking. J. Korean Soc. People Plant Environ. 17(1):9-14. https://doi.org/10.11628/kspp e.2014.17.1.009

Jeong, S.J., S.M. Lee, Y.J. Song, H.J. Son, J.W. Lee, and J.H. Moon. 2011. Effects of horticulture-Korean language integrated program on expressive language, language comprehensive ability and nature friendly environment attitude of young children (Abstr.). Korean J. Hortic. Sci. Technol. 29(Suppl. I):206.

Jeong, S.J., Y.J. Song, M.S. Kim, M.I. Jeong, and H.D. Kim. 2009. Effect of young children's horticultural program on the young children's natural-environment attitude, scientific attitude and exploration ability, and emotional intelligence. J. Korean Soc. People Plant Environ. 12(6):37-43.

Jung, S.J., K.S. Eom, and B.S. Kim. 2017. The effect of horticultural activities of early childhood infants on emotional intelligence, peer competence, and self-esteem. J. Eco Early Child. Educ. Care 16(4):127-149.

Kang, M.H., Y.J. Jang, M.O. Mun, S.R. Choi, and E.J. JO. 2003. Child studies education. Paju, Korea: Yangseowon.

Kim, E. and Y. Kim. 2018. The effects of children's environment friendly attitude and scientific inquiry skills through the natural environment education based on education for sustainable development. J. Future Early Child. Educ. 25(3):227-248. https://doi.org/10.22155/JF ECE.25.3.227.248

Kim, H.J. 2013. A study of recognition of preschoolers' teachers and their parents on the forest kindergarten:
Based on the forest early childhood educational institutes. Master's thesis, Dongguk University, Seoul, Korea.

Kim, H.K., Y.J. Song, Y.M. Im, H.J. Kim, J.S. Kim, and J.O. Park. 2013. Social studies for young children. Seoul, Korea: Hakjisa.

Kim, K.S. and M.J. Park. 2013. Exploring the meanings of experiences with nature-friendly activities on young children's characters. J. Korea Open Assoc. Early Child. Educ. 18(2):359-387.

Kim, S.H. 2012. Preschool teachers' recognition of environment by horticultural program. Master's thesis, Korea University, Seoul, Korea.

Kim, S.H. and E.J. Park. 2014. The influence of nature experience activities based on ecological picture books on both scientific research skills and natural friendly attitude for the children. J. Early Child. Educ. Educare Welf. 18(1):59-88.

Kim, S.J., M.J. Lee, and S.B. Choi. 2017. A study on the authority and trust of experts in Korean society. Ewha J. Soc. Sci. 33(2):177-215. https://doi.org/10.16935/ejss. 2017.33.2.006

Kim, Y. 2019. Differences in life satisfaction and the perception of growing plants according to the status of growing indoor plants. Master's thesis, Korea University, Seoul, Korea

Korea Development Institute. 2017. A study on the role of parents and the improvement of parental education for the development of infant (Report No. 79). Sejong, Korea: Author. Retrieved from http://www.kdi.re.kr

Kwon, J.Y., M.R. Chung, and B.S. Yee. 2015. The influence of fathers ' play interaction on the cognitive, motor and language development of young children. Korean J. Early. Child. Educ. 35(1):333-350. https://doi.org/10.18023/kje ce.2015.35.1.015

Lee, H.J. 2017. The effect of cooking activities on the happiness and emotional intelligence of infant in urban farm boxes. Master's thesis, Ajou University, Suwon, Korea.

Louv, R. 2007. Last child in the woods: Saving our children from nature-deficit disorder. Chapel Hill, NC: Algonquin Books.

Oh, Y.H. 2011. Meanings of nature-friendly early childhood curriculum on children's development: Focusing on 'flower and tree' related activities. J. Korea Open 
Assoc. Early Child. Educ. 16(1):47-70.

Park, G.H. 2001. A study of status and several points in horticulture experience study of the preschool: by Cheonan. Master's thesis, Dankook University, Yongin, Korea.

Park, H.S. 2010. A study on developing and applying environment education programs based on family-partnership for young children's environmental literacy. Korean J. Early. Child. Educ. 30(3):215-237. https://doi.org/10.18023/kjece.2010.30.3.010

Rural Development Administration. 2008. Manual for the use of guidance on rural education farms. Regional Academy Training Farm Center. Jeonju, Korea: Author.
Rural Development Administration. 2018. 2018 Guidebook on quality certification of rural education farm. Jeonju, Korea: Author.

Son, K.C. 2014. Indoor plants save people. Seoul, Korea: Joongang Life Publishing Co.

Son, N.S. and S.H. Lee. 2008. Effects of the parenting attitude on children's social abilities from age 4 to age 6. J. Future Early Child. Educ. 15(2):49-77.

White. R. 2004. Young children's relationship with nature: Its importance to children's development \& the earth's future. Kansas City, MO, USA: White Hutchinson Leisure \& Learning Group. 